\title{
The Relationship of Orofacial Pain and Dental Health Status and Oral Health Behaviours in Facial Burn Patients
}

\author{
Farooq Ahmad Chaudhary $\left(D^{D},{ }^{1}\right.$ Basaruddin Ahmad $\left(D,{ }^{2}\right.$ Muhammad Qasim Javed (iD, ${ }^{3}$ \\ Shaikh Shoeb Yakub, ${ }^{3}$ Bilal Arjumand, ${ }^{3}$ Asma Munir Khan, ${ }^{3}$ and Saeed Mustafa ${ }^{1}$ \\ ${ }^{1}$ School of Dentistry, Shaheed Zulfiqar Ali Bhutto Medical University, Islamabad, Pakistan \\ ${ }^{2}$ School of Dental Sciences, Universiti Sains Malaysia, Kubang Kerian, Malaysia \\ ${ }^{3}$ Department of Conservative Dental Sciences, College of Dentistry, Qassim University, Al-Qassim, Saudi Arabia
}

Correspondence should be addressed to Farooq Ahmad Chaudhary; chaudhary4@hotmail.com

Received 7 January 2021; Revised 24 February 2021; Accepted 3 May 2021; Published 8 May 2021

Academic Editor: Federica Galli

Copyright (c) 2021 Farooq Ahmad Chaudhary et al. This is an open access article distributed under the Creative Commons Attribution License, which permits unrestricted use, distribution, and reproduction in any medium, provided the original work is properly cited.

\begin{abstract}
This study aims to examine the association of orofacial pain and oral health status and oral health behaviours in facial burn patients. The participants in this cross-sectional study were randomly recruited from the Burn Care Center, Institute of Medical Sciences, Islamabad, Pakistan. An intraoral evaluation was carried out to record the DMFT and OHI-S. A self-administered questionnaire was used to collect information on sociodemographic status, brushing frequency, and dental visits. Orofacial pain during mandibular movement was assessed using the Visual Analogue Scale (VAS). Psychological status was assessed using the Generalized Anxiety Disorder Scale and Impact of Events Scale. ANOVA and simple and multiple linear regression tests were used to analyse the data. From the 90 facial burn patients included, the majority were below 34 years of age, female, single or divorced, and unemployed. The mean DMFT was 10.7 , and $71 \%$ had poor oral hygiene. $56 \%$ of the participants had moderate-to-severe anxiety, and $68 \%$ had posttraumatic stress disorder. $53 \%$ of the participants had moderate-to-severe pain during mouth opening or moving the mandible with a mean score of 41.5. Analyses showed that orofacial pain was associated with less frequent brushing, irregular dental visits, greater DMFT score, and more plaque accumulation (OHI-S). It was also associated with employment status, the severity of a burn, anxiety, and stress. The treatment and management of dental and oral conditions in burn patients need judicious balance in controlling and accurate assessment of the pain and improving psychological problems in burn patients.
\end{abstract}

\section{Introduction}

Burn injuries are an example of the most debilitating physical and traumatic injuries that can potentially lead to severe physical (scars, deformities, disfigurements, and disabilities) and psychological morbidity (distress, suicidal ideation, anxiety, and posttraumatic stress) and mortality [1]. The prevalence of burn cases is declining in the developed countries, but it remains a public health concern in developing countries [2]. According to the World Health Organization (WHO), approximately 11 million cases of burn injuries, including 180,000 fatalities, occur annually worldwide and $90 \%$ of them are in low- and middle-income countries [1].
Burn patients go through a long journey towards recovery which lasts for years or decades while enduring acute, healing, and rehabilitation phases [3]. The physical complications and impairments caused by burn injuries depend upon their cause, severity, depth, and location of the burn on the body, treatment, and postburn care [3]. The major focus of burn management includes pain, infection, hypertrophic scarring, wound healing, and psychological trauma [4]. Apart from the acute posttraumatic pain, the most frequent complaint by patients is the pain caused by mechanical hyperalgesia at the affected burn area. Over time, it can lead to paresthesia, dysesthesia, loss of sensibility, and chronic pain and further worsens the psychological impact [5]. Chronic pain is another significant problem and source of 
discomfort and concern among burn survivors in their journey towards recovery, affecting $52 \%$ over an average of 12 years after the incident [6].

A burn to the orofacial region involving the lips and mouth has compounding impacts. The skin contraction or tightening during the healing process and scarring can lead to lip distortion and microstomia [7]. This, in turn, limits mouth opening and subsequently causes pain and discomfort while performing daily activities such as speaking, mastication, swallowing, and oral hygiene care. In a study, facial burn patients were observed to be uncomfortable and in pain when asked to open their mouth wide during the oral examination but no pain assessment was performed [8]. Pain trajectories also worsen in orofacial burn survivors who have a high level of stress, anxiety, and depression and exacerbate the previously undermined psychological conditions caused by the event [9]. Despite this understanding, the literature lacks a discussion on the impact of orofacial pain related to facial burn complications on oral condition. Hence, this study aimed to investigate the relationship between orofacial pain and oral health status and oral health behaviours in facial burn patients.

\section{Methods}

In this cross-sectional study, burn patients who visited the Burn Care Center, Pakistan Institute of Medical Sciences, Islamabad, for follow-up were randomly recruited after the ethical approval was approved from the Ethics Review Board, Shaheed Zulfiqar Ali Bhutto Medical University, Islamabad, Pakistan (F.1-23/2020/ERB/SZABMU). Participants over the age of 15 years with a burn injury to the face and neck region for more than one year and able to feed exclusively by mouth were included in this study. The participants were briefed about the purpose of the study. Written informed consent was obtained before data collection from all the participants and their parents in case of minors. All the participants underwent an intraoral examination by one investigator to record the dental (DMFT) and oral hygiene (OHI-S) status using a standard survey method by the WHO $[10,11]$. The DMFT is a dental caries severity index that expresses the total number of Decayed (D), Missing (M), and Filled (F) teeth, and the total score is calculated by adding all the individual teeth scores that range from 0 to 32 [10]. The Simplified Oral Hygiene Index (OHI$S$ ) is used to record the level of oral hygiene by assessing the debris, stains, and calculus on specific surfaces of six index teeth, with total scores ranging from 0 to 6 , the latter representing the worst oral hygiene [11].

The participants also completed self-administered questionnaires that included information related to sociodemographic (age group, gender, and marital status), tooth brushing frequency (none, once, twice, or more), and dental check-ups in the past year (Yes or No). The information regarding the severity of burn injury (first-, second-, and third-degree burn) and time elapsed after that burn injury was taken from the patients' medical records.

Pain assessment was carried out by asking the participants to open the mouth widely and perform mandibular movements and then rate the pain experience by making " $X$ " on the Visual Analogue Scale (VAS) [12, 13]. The VAS, a simple and commonly used analogue scale, comprises a horizontal line measuring $100 \mathrm{~mm}$ with "no pain" marked at $0 \mathrm{~mm}$ and "worst pain imaginable" at $100 \mathrm{~mm}$. The pain score is the distance measured from $0 \mathrm{~mm}$ to the point " $X$ " and ranges between 0 and 100, with a higher score suggesting greater pain intensity. The score was categorized as no pain (0 to $4 \mathrm{~mm}$ ), mild pain $(5-44 \mathrm{~mm})$, moderate pain $(45-74 \mathrm{~mm})$, and severe pain $(75-100 \mathrm{~mm})$ [13]. The psychological status was assessed using the Urdu version of the Generalized Anxiety Disorder Scale (GAD-7) and Impact of Events Scale (IES) [14, 15]. The 7-item GAD-7 questionnaire assesses anxiety symptoms on a four-point Likert scale, from 0 (not at all) to 3 (almost every day). The GAD-7 score is obtained by adding all the responses and ranges from 0 to 21 , whereby a greater value indicates more severe anxiety. It was categorized into four severity levels: minimal (0-4), mild (5-9), moderate (10-14), and severe (14-20) for descriptive purposes [14]. The Urdu version of GAD-7 has been validated and shown to have excellent internal constancy (Cronbach's alpha: 0.92) [14]. The 15-item IES questionnaire assesses posttraumatic stress disorder (PTSD) caused by traumatic events. The revised Urdu version of IES-R used in this study contains 7 additional items that cover three clusters of PTSD symptoms: intrusion, avoidance, and hyperarousal. The response of each item is scored on a fivepoint Likert scale, from 0 (not at all) to 4 (extremely). The final score ranges from 0 to 88 . A threshold score $>20$ indicates that the individual has PTSD [15].

2.1. Statistical Analysis. Descriptive analysis was carried out to describe the sample and summary statistics of measures included in the study. Associations between pain related to mouth opening, jaw movement, and the factors were examined using simple and multiple linear regression. All ordinal variables were treated as continuous variables to examine the effect linear trend of exposure variables. Analyses were performed at a $5 \%$ significance level and carried out using IBM SPSS software v26.0.

\section{Results}

A total of 95 patients with a facial burn were invited to participate and 90 patients had consented and completed the oral examination and self-administrated questionnaires with a response rate of $94.7 \%$. The sample included a high percentage of females (67\%), below 25 years of age (41.1\%), single, divorced, or widowed (71\%), and unemployed (70\%) individuals (Table 1). Most subjects had second-degree burn injuries $(60 \%)$ and had the injury for $2-4$ years $(71 \%)$. The participants had high DMFT (mean $=10.7$ ), and $71.1 \%$ had poor oral hygiene. More than half of the sample practiced teeth brushing once a day (61\%) and did not have a dental check-up in the past year (88\%). Slightly more than half of the participants had moderate-to-severe anxiety (53\%) and about two-thirds had posttraumatic stress disorder (68\%). About half of the participants had moderate-to-severe pain 
TABLE 1: Sociodemographic characteristics of the participants $(N=90)$

\begin{tabular}{|c|c|}
\hline Characteristics & Number (\%) \\
\hline \multicolumn{2}{|l|}{ Age } \\
\hline $15-24$ & $37(41.1)$ \\
\hline $25-34$ & $22(24.4)$ \\
\hline $35-44$ & $17(18.9)$ \\
\hline $45+$ & $14(15.6)$ \\
\hline \multicolumn{2}{|l|}{ Gender } \\
\hline Male & $30(33.3)$ \\
\hline Female & $60(66.7)$ \\
\hline \multicolumn{2}{|l|}{ Marital status } \\
\hline Single/divorced/widowed & $64(71.1)$ \\
\hline Married & $26(28.9)$ \\
\hline \multicolumn{2}{|l|}{ Employment status } \\
\hline Full-time job & $18(20.0)$ \\
\hline Part-time job & $9(10.0)$ \\
\hline Unemployed & $63(70.0)$ \\
\hline \multicolumn{2}{|l|}{ Degree of burn injury } \\
\hline First-degree burn & $11(12.2)$ \\
\hline Second-degree burn & $54(60.0)$ \\
\hline Third-degree burn & $25(27.8)$ \\
\hline \multicolumn{2}{|l|}{ Time since burn injury } \\
\hline $1-2$ years & $16(17.8)$ \\
\hline $2-3$ years & $38(42.2)$ \\
\hline $3-4$ years & $26(28.9)$ \\
\hline $4+$ years & $10(11.1)$ \\
\hline DMFT mean (SD) & $10.7(2.17)$ \\
\hline \multicolumn{2}{|l|}{ OHI-S } \\
\hline Good & $8(8.9)$ \\
\hline Fair & $18(20.0)$ \\
\hline Poor & $65(71.1)$ \\
\hline \multicolumn{2}{|c|}{ Daily frequency of toothbrushing } \\
\hline None & $25(27.8)$ \\
\hline Once a day & $54(60.6)$ \\
\hline Twice a day & $9(10.0)$ \\
\hline More than twice & $2(2.2)$ \\
\hline \multicolumn{2}{|l|}{ Dental check-ups } \\
\hline Yes & $11(12.2)$ \\
\hline No & $79(87.8)$ \\
\hline GAD-7, mean (SD) & $10.26(4.18)$ \\
\hline Normal & $11(12.2)$ \\
\hline Mild & $29(32.2)$ \\
\hline Moderate & $32(35.6)$ \\
\hline Severe & $18(20.0)$ \\
\hline $\begin{array}{l}\text { IES, mean (SD) } \\
\text { (S) }\end{array}$ & $36.3(18.8)$ \\
\hline No PTSD & $29(32.2)$ \\
\hline Yes PTSD & $61(67.8)$ \\
\hline Pain, mean (SD) & $41.5(20.6)$ \\
\hline No pain & $5(5.6)$ \\
\hline Mild & $37(41.1)$ \\
\hline Moderate & $39(43.3)$ \\
\hline Severe & $9(10.0)$ \\
\hline
\end{tabular}

during mouth opening or moving the mandible (53\%) with a mean score of 41.5 .

The simple linear regression analysis showed that pain during movement of the mouth was associated with employment status, the severity of the injury, and time since the incidence (Table 2). More severe pain is associated with less frequent brushing, visits to the dentist in the past year, and greater DMFT score, plaque accumulation, anxiety, and stress.

The standardised coefficient for the DMFT in the multiple linear regression analysis was the largest compared to other factors, indicating that caries experience was the most important factor associated with pain.

\section{Discussion}

This is the first study that examines the relationship between orofacial pain related to mandibular movement and dental health status and oral health behaviours in facial burn patients and it found a significant association between them. Greater pain levels are associated with poorer dental and oral hygiene status, less frequent tooth brushing, and no visit to the dentist in the past year. The dental health status and oral hygiene were similar to a previous study on facial burn patients (mean DMFT =10.9; poor OHI-S: 66.1\%) [8]. The strong contribution of caries experience in the multivariate analysis to explain the variation in pain suggests a plausible link between orofacial pain and poor oral health conditions in patients with a facial burn injury. A burn to the facial region causes disfigurement of appearance and, in severe cases, physical impairment as a result of skin, muscles, and mucosal scarring. Tissue contraction and scarring limit mouth opening and movement and cause pain on forced opening [16]. These limit access to the oral cavity and make it extremely difficult for the patients to maintain good oral hygiene practice. Limited jaw movement also affects their chewing ability, adversely affects saliva secretion, and impairs the natural mechanism of mechanical plaque removal with the help of food during chewing [17]. A high level of oral function impairment has been linked to pain in patients with temporomandibular disorders and it could be worse in facial burn patients whose temporomandibular joint is affected [18]. Impaired chewing capability is reported to be related to TMJ pain and limitation in mouth opening and poor oral and general health status $[19,20]$. Thus, the orofacial pain, coupled with poor oral health behaviours of the participants, increases the risk of developing caries. A regular visit to the dentist is highly recommended for the patients because, besides providing restorative care, dentists also can help in improving oral hygiene care such as the appropriate tooth brushing techniques for their condition and provide counselling on the caries risk factors.

This study also found that pain is more severe in older participants and those with a more recent injury, anxiety, and stress. Being older does not lower pain tolerance, likely due to ineffective pain inhibitory processes [21]. Nevertheless, the pain tends to decrease as time passes as they get used to it over time $[18,21]$. The associations between pain and anxiety and stress found in the study are in line with earlier reports; the pain may lead to prolonged stress response, delay in healing, and longer recovery time [22, 23]. Depression and negative thoughts are reported in burn patients with high-intensity pain [24]. Data from this study 
TABLE 2: Association of pain with sociodemographic, burn characteristic, and psychological measures.

\begin{tabular}{|c|c|c|c|}
\hline & $\begin{array}{l}\text { Pain score } \\
\text { Mean (SD) }\end{array}$ & $\begin{array}{c}\mathrm{SLR}^{1} \\
\mathrm{RC}^{3}(\mathrm{se}) \\
P\end{array}$ & $\begin{array}{c}\mathrm{MLR}^{2} \\
\mathrm{RC}^{3}(95 \% \mathrm{CI}) \\
\mathrm{SC}^{4} \\
P\end{array}$ \\
\hline \multicolumn{4}{|l|}{ Age } \\
\hline $15-24$ & $42.6(16.8)$ & $2.76(1.96)$ & $1.61(-0.17,3.40)$ \\
\hline $25-34$ & $31.5(20.7)$ & 0.163 & 0.09 \\
\hline $35-44$ & $42.5(21.3)$ & & 0.08 \\
\hline $45+$ & $53.2(23.6)$ & & \\
\hline \multicolumn{4}{|l|}{ Gender } \\
\hline Male & $41.4(21.2)$ & $0.13(4.64)$ & \multirow{2}{*}{-} \\
\hline Female & $43.6(20.5)$ & 0.97 & \\
\hline \multicolumn{4}{|l|}{ Marital status } \\
\hline Single/divorced/widowed & $40.2(19.4)$ & $4.68(4.81)$ & \multirow{2}{*}{-} \\
\hline Married & $44.9(23.6)$ & 0.3 & \\
\hline \multicolumn{4}{|l|}{ Employment status } \\
\hline Full-time job & $15.4(7.57)$ & $17.3(1.9)$ & $4.83(1.73,7.93)$ \\
\hline Part-time job & $33.2(20.1)$ & 0.001 & 0.19 \\
\hline Unemployed & $50.2(16.1)$ & & 0.003 \\
\hline \multicolumn{4}{|l|}{ Degree of burn injury } \\
\hline First-degree burn & $10.0(7.08)$ & $20.2(2.85)$ & $5.49(1.89,9.09)$ \\
\hline Second-degree burn & $41.7(14.6)$ & 0.001 & 0.16 \\
\hline Third-degree burn & $55.0(21.3)$ & & 0.003 \\
\hline \multicolumn{4}{|l|}{ Time since burn injury } \\
\hline 1-2 years & $60.5(19.3)$ & $-13.4(1.98)$ & $-2.43(-4.90,0.04)$ \\
\hline $2-3$ years & $45.9(13.6)$ & 0.001 & -0.11 \\
\hline 3-4 years & $30.8(18.4)$ & & 0.05 \\
\hline $4+$ years & $22.1(20.2)$ & & Om9 \\
\hline \multicolumn{4}{|l|}{ Tooth brushing } \\
\hline None & $62.2(12.2)$ & $-22.5(2.21)$ & $-5.96(-9.90,-2.02)$ \\
\hline Once & $38.0(15.1)$ & 0.001 & -0.19 \\
\hline Twice & $12.2(11.3)$ & & 0.003 \\
\hline More than twice & $9.0(4.24)$ & & \\
\hline \multicolumn{4}{|l|}{ Dental visits } \\
\hline Yes & $22.0(22.1)$ & $22.1(6.25)$ & \multirow{2}{*}{-} \\
\hline No & $44.2(19.0)$ & 0.001 & \\
\hline & & $7.40(0.63)$ & $3.26(2.11,4.42)$ \\
\hline DMFT & $41.5(20.6)$ & 0.001 & 0.34 \\
\hline & & & $<0.001$ \\
\hline \multicolumn{4}{|l|}{ OHI-S } \\
\hline Good & $13.0(9.29)$ & $18.5(2.77)$ & \\
\hline Fair & $27.8(17.4)$ & 0.001 & - \\
\hline Poor & $48.8(17.4)$ & & \\
\hline \multicolumn{4}{|l|}{ GAD-7 } \\
\hline Normal & $24.2(19.2)$ & $14.1(1.78)$ & $4.24(1.83,6.65)$ \\
\hline Mild & $31.1(19.6)$ & 0.001 & 0.19 \\
\hline Moderate & $43.1(11.4)$ & & 0.001 \\
\hline Severe & $65.9(11.3)$ & & \\
\hline \multicolumn{4}{|l|}{ IES-R } \\
\hline No PTSD & $20.7(13.9)$ & $30.6(3.36)$ & - \\
\hline Existing PTSD & $51.4(15.3)$ & 0.001 & \\
\hline
\end{tabular}

${ }^{1}$ Simple linear regression. ${ }^{2}$ Multiple linear regression. ${ }^{3}$ Regression coefficient. ${ }^{4}$ Standardised coefficient.

also suggests that poor dental health status, less frequent tooth brushing, and irregular dental visits are associated with anxiety and stress (Table 3 ), consistent with earlier reports $[25,26]$.
Unemployment is another social characteristic related to higher pain expression. Chronic pain can impair working lives through a sudden change in the working environment and job loss [27]. The change in the physical appearance of 
TABLE 3: Association of psychological measures with oral health behaviours and dental status.

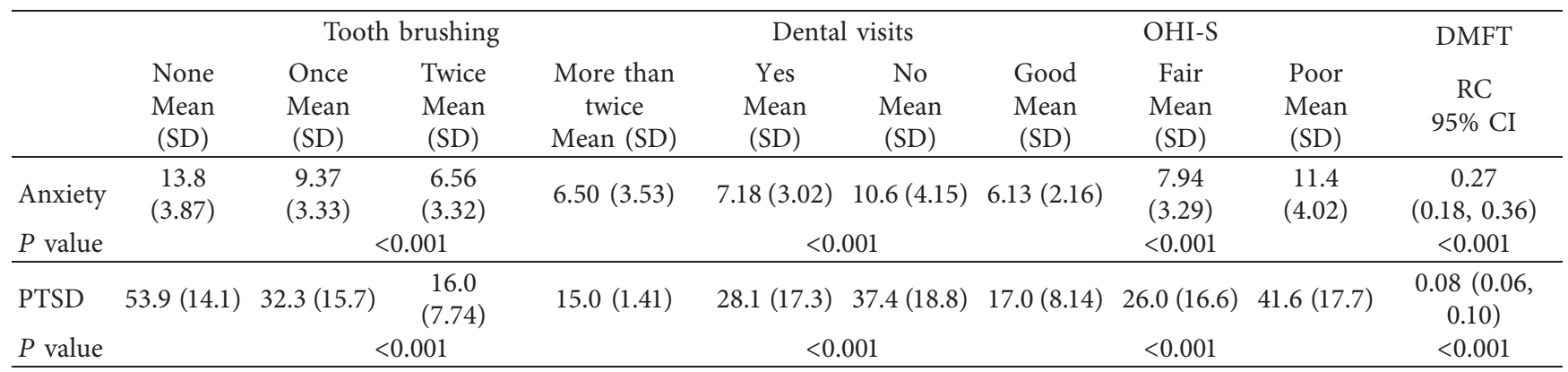

these patients makes it difficult for them to find a new job or return to an old one. About $10-30 \%$ of burn survivors either do not return to work or lose the ability to work due to physical impairments injury [28]. Unemployment, brought about by disfigurement in appearance and lack of job opportunities for burn survivors who are already suffering from financial burden due to expensive and long burn care treatments, further worsens the psychological conditions of burn victims who are already distressed by the incident and its sequela [28-30]. Factors including stress from the burn incident and unemployment, education level, and having low income and older age have been associated with greater risk of pain in the jaw and face region; they are also linked to a greater risk of having poor oral conditions [8].

The findings of this study should be interpreted with caution. Limited causal inference can be made due to the cross-sectional design and associations are based only on statistical analysis. The severity of pain in relation to the need for medication and whether it truly affects oral hygiene care were not assessed. A qualitative study to assess how pain influences oral hygiene care and the extent of its effect is recommended to justify the posit. Among the greatest challenges of this study is to gain the trust of the participants who suffer from physical and psychosocial problems that make them nervous, cautious, shy, hesitant, and scared and seek sensitive information related to the dire experience and ask them to perform manoeuvres that are uncomfortable and painful.

\section{Conclusion}

This study suggests that there is a link between orofacial pain from jaw movement and oral health behaviours and poor oral conditions in facial burn patients. Factors including burn severity, time since burn injury, and psychosocial problems are also associated with orofacial pain. The findings can raise the awareness of oral health care professionals regarding the complex and multifactorial nature of dental and oral health problems in burn patients and help in preparing safe and effective strategies and practice guidelines for the care of patients with a facial burn injury. Treatment and management of dental and oral conditions in these patients require judicious balance in controlling and accurate assessment of the pain while at the same time addressing the psychological issues. Further investigations on the negative impact of orofacial pain and psychological conditions on oral health status and behaviours in burn patients are recommended.

\section{Data Availability}

The datasets used and/or analysed during the current study are available from the corresponding author upon reasonable request.

\section{Conflicts of Interest}

The authors declare that they have no conflicts of interest.

\section{Authors' Contributions}

Farooq Ahmad Chaudhary and Basaruddin Ahmad conceived the idea, performed data analyses, and revised the manuscript; Muhammad Qasim Javed and Bilal Arjumand helped in collecting data and its analyses. Shaikh Shoeb Yakub, Asma Munir Khan, and Saeed Mustafa wrote the first draft of the manuscript and revised the final manuscript.

\section{References}

[1] C. Smolle, J. Cambiaso-Daniel, A. A. Forbes et al., "Recent trends in burn epidemiology worldwide: a systematic review," Burns, vol. 43, no. 2, pp. 249-257, 2017.

[2] N.-A. Latifi, H. Karimi, S. A. Motevalian, and M. Momeni, "Economical burden of burn injuries in a developing country," Journal of Burn Care \& Research, vol. 38, no. 6, pp. e900-e905, 2017.

[3] O. Tengvall, M. Wickman, and Y. Wengström, "Memories of pain after burn injury-the patient's experience," Journal of Burn Care \& Research, vol. 31, no. 2, pp. 319-327, 2010.

[4] G. J. Summer, K. A. Puntillo, C. Miaskowski, P. G. Green, and J. D. Levine, "Burn injury pain: the continuing challenge," The Journal of Pain, vol. 8, no. 7, pp. 533-548, 2007.

[5] A. Malenfant, R. Forget, R. Amsel, J. Papillon, J.-Y. Frigon, and M. Choinière, "Tactile, thermal and pain sensibility in burned patients with and without chronic pain and paresthesia problems," Pain, vol. 77, no. 3, pp. 241-251, 1998.

[6] E. Gauffin, C. Öster, F. Sjöberg, B. Gerdin, and L. Ekselius, "Health-related quality of life (EQ-5D) early after injury predicts long-term pain after burn," Burns, vol. 42, no. 8, pp. 1781-1788, 2016.

[7] M. E. Dougherty and G. D. Warden, "A thirty-year review of oral appliances used to manage microstomia, 1972 to 2002," Journal of Burn Care \& Rehabilitation, vol. 24, no. 6, pp. 418-431, 2003. 
[8] F. A. Chaudhary, B. Ahmad, and U. Bashir, "Dental health status and oral health behaviours of patients with facial burn in Pakistan," BMC Oral Health, vol. 19, no. 1, p. 127, 2019.

[9] A. J. Means-Christensen, P. P. Roy-Byrne, C. D. Sherbourne, M. G. Craske, and M. B. Stein, "Relationships among pain, anxiety, and depression in primary care," Depression and Anxiety, vol. 25, no. 7, pp. 593-600, 2008.

[10] W. H. Organization, Oral Health Surveys: Basic Methods, World Health Organization, Geneva, Switzerland,, 2013.

[11] J. G. Greene and J. R. Vermillion, "The simplified oral hygiene index," The Journal of the American Dental Association, vol. 68, no. 1, pp. 7-13, 1964.

[12] J. Katz and R. Melzack, "Measurement of pain," Surgical Clinics of North America, vol. 79, no. 2, pp. 231-252, 1999.

[13] G. A. Hawker, S. Mian, T. Kendzerska, and M. French, "Measures of adult pain: visual analog scale for pain (VAS pain), numeric rating scale for pain (NRS pain), McGill pain questionnaire (MPQ), short-form McGill pain questionnaire (SF-mpq), chronic pain grade scale (CPGS), short form-36 bodily pain scale (SF)," Arthritis Care \& Research, vol. 63, no. S11, pp. S240-S252, 2011.

[14] S. Ahmad, S. Hussain, F. S. Shah, and F. Akhtar, "Urdu translation and validation of GAD-7: a screening and rating tool for anxiety symptoms in primary health care," JPMA. The Journal of the Pakistan Medical Association, vol. 67, no. 10, pp. 1536-1540, 2017.

[15] M. Tareen, C. McDowell, K. Naqvi et al., "Evaluation of an Urdu version of the impact of event scale-revised," International Psychiatry, vol. 9, no. 1, pp. 20-22, 2012.

[16] I. Parry, K. Walker, J. Niszczak, T. Palmieri, and D. Greenhalgh, "Methods and tools used for the measurement of burn scar contracture," Journal of Burn Care \& Research, vol. 31, no. 6, pp. 888-903, 2010.

[17] M. Addy, E. Perriam, and A. Sterry, "Effects of sugared and sugar-free chewing gum on the accumulation of plaque and debris on the teeth," Journal of Clinical Periodontology, vol. 9, no. 4, pp. 346-354, 1982.

[18] G.-H. E. Tjakkes, J.-J. Reinders, E. M. Tenvergert, and B. Stegenga, "TMD pain: the effect on health related quality of life and the influence of pain duration," Health and Quality of Life Outcomes, vol. 8, no. 1, p. 46, 2010.

[19] H. Miura, M. Kariyasu, K. Yamasaki, Y. Arai, and Y. Sumi, "Relationship between general health status and the change in chewing ability: a longitudinal study of the frail elderly in Japan over a 3-year period," Gerodontology, vol. 22, no. 4, pp. 200-205, 2005.

[20] F. Chaudhary, B. Ahmad, D. Butt, S. Hameed, and U. Bashir, "Normal range of maximum mouth opening in pakistani population: a cross-sectional study," Journal of International Oral Health, vol. 11, no. 6, p. 353, 2019.

[21] S. Lautenbacher, J. H. Peters, M. Heesen, J. Scheel, and M. Kunz, "Age changes in pain perception: a systematic-review and meta-analysis of age effects on pain and tolerance thresholds," Neuroscience \& Biobehavioral Reviews, vol. 75, pp. 104-113, 2017.

[22] A. J. Esfahlan, M. Lotfi, V. Zamanzadeh, and J. Babapuor, "Burn pain and patients' responses," Burns, vol. 36, no. 7, pp. 1129-1133, 2010.

[23] N. H. Corry, B. Klick, and J. A. Fauerbach, "Posttraumatic stress disorder and pain impact functioning and disability after major burn injury," Journal of Burn Care \& Research, vol. 31, no. 1, pp. 13-25, 2010.
[24] J. F. Ulmer, "An exploratory study of pain, coping,and depressed mood following burn injury," Journal of Pain and Symptom Management, vol. 13, no. 3, pp. 148-157, 1997.

[25] S. Anttila, M. Knuuttila, P. Ylöstalo, and M. Joukamaa, "Symptoms of depression and anxiety in relation to dental health behavior and self-perceived dental treatment need," European Journal of Oral Sciences, vol. 114, no. 2, pp. 109-114, 2006.

[26] W. Sohn and A. I. Ismail, "Regular dental visits and dental anxiety in an adult dentate population," The Journal of the American Dental Association, vol. 136, no. 1, pp. 58-66, 2005.

[27] H. Breivik, B. Collett, V. Ventafridda, R. Cohen, and D. Gallacher, "Survey of chronic pain in Europe: prevalence, impact on daily life, and treatment," European Journal of Pain, vol. 10, no. 4, pp. 287-333, 2006.

[28] M. B. Klein, D. L. Lezotte, J. A. Fauerbach et al., "The national institute on disability and rehabilitation research burn model system database: a tool for the multicenter study of the outcome of burn injury," Journal of Burn Care \& Research, vol. 28, no. 1, pp. 84-96, 2007.

[29] F. A. Chaudhary, B. Ahmad, D. Q. Butt, S. Hameed, and U. Bashir, "The cultural adaptation and validation of an Urdu version of the satisfaction with appearance scale (SWAP-U) for Pakistani burn patients," Burns Open, vol. 3, no. 3, pp. 83-88, 2019.

[30] P. C. Esselman, S. Wiechman Askay, G. J. Carrougher et al., "Barriers to return to work after burn injuries," Archives of Physical Medicine and Rehabilitation, vol. 88, no. 12, pp. S50-S56, 2007. 